\title{
Regulation of miR-155 affects the invasion and migration of gastric carcinoma cells by modulating the STAT3 signaling pathway
}

\author{
HUA WEI ${ }^{1 *}$, YAN $\mathrm{LI}^{2 *}$, QIANG NING ${ }^{3}$ and ZHI-MIN SUO ${ }^{2}$ \\ Departments of ${ }^{1}$ Endoscopy and ${ }^{2}$ Gastroenterology, Huaihe Hospital Affiliated to Henan University, Kaifeng, \\ Henan 475000; ${ }^{3}$ Department of Endoscopy, Third Hospital of Wafangdian, Dalian, Liaoning 116300, P.R. China
}

Received April 1, 2016; Accepted November 2, 2017

DOI: $\quad 10.3892 / \mathrm{ol} .2018 .9152$

\begin{abstract}
Studies investigating the effects of microRNA (miR)-155 on the behavior of tumor cells have concentrated primarily on proliferation and apoptosis. The aim of the present study was to investigate the effect of miR-155 inhibitor on the metastatic and invasive ability of gastric carcinoma cells and whether this effect is mediated via the signal transduction and activators of transcription 3 (STAT3) signaling pathway. The miR-155 inhibitor and miR-155 negative control (NC) were transfected into the AGs and MKN-45 cell lines. The migratory and invasive abilities of the cells were analyzed. The level of phosphorylated (p-)STAT3 and the expression levels of matrix metalloproteinases (MMPs), vascular endothelial growth factor (VEGF) and suppressor of cytokine signaling 1 (SOCS1) were also detected. For the AGS cell line, the cell counts (mean \pm standard deviation) for the Transwell migration assay were $98.99 \pm 9.13$ in the miR-155 NC group and $45.32 \pm 4.32$ in the miR-155 inhibitor group $(\mathrm{P}<0.01)$. For the MKN-45 cell line, the cell counts for the migration assay were $129.99 \pm 10.12$ and $50.36 \pm 5.2$ in the miR-155 NC and miR-155 inhibitor groups, respectively $(\mathrm{P}<0.01)$. The cell counts of the AGS cell line for the invasion assay were $70.25 \pm 7.94$ in the miR-155 NC group and $40.68 \pm 4.73$ in the miR-155 inhibitor group $(\mathrm{P}<0.05)$. For the MKN-45 cell line, the cell counts for the invasion assay were $84.63 \pm 8.12$ and $40.35 \pm 4.29$ in the miR-155 NC and miR-155 inhibitor groups, respectively $(\mathrm{P}<0.05)$. Transfection with the miR-155 inhibitor was able to significantly decrease the level of p-STAT3 in the AGS
\end{abstract}

Correspondence to: Professor Zhi-Min Suo, Department of Gastroenterology, Huaihe Hospital Affiliated to Henan University, 115 Ximen Street, Kaifeng, Henan 475000, P.R. China

E-mail: suo30zhi36qm@sina.com

${ }^{*}$ Contributed equally

Key words: microRNA-155, gastric carcinoma, vascular endothelial growth factor, suppressor of cytokine signaling 1, migration, invasion and MKN-45 cell lines compared with the negative control group (all $\mathrm{P}<0.05$ ). The levels of MMP2 and MMP9 expression were decreased following transfection with miR-155 in AGS and MKN-45 cells (both $\mathrm{P}<0.05$ ). Notably, transfection with the miR-155 inhibitor was able to decrease the level of VEGF expression, whilst increasing the SOCS1 expression level compared with the negative control group (both $\mathrm{P}<0.05$ ). Additionally, the downregulation of miR-155 expression in gastric carcinoma cell lines was able to significantly decrease the expression of VEGF, MMP2 and MMP9, thereby inhibiting the invasion and metastasis of gastric carcinoma cells.

\section{Introduction}

Gastric cancer is one of the most common malignant tumor types globally. The morbidity of gastric carcinoma in China, particularly in rural areas, is one of the top leading causes of cancer mortality, which poses a huge threat to human health (1). The majority of patients with early gastric carcinoma are able to survive $>5$ years or even achieve remission following surgical treatments. However, the onset of gastric carcinoma is latent, symptoms and physical signs at the early stages of the disease are not significant, and the malignancy develops rapidly (2). For these reasons, $>50 \%$ of patients present with advanced stages of the disease at the point of diagnosis, and radical surgical treatment is unsuitable for this group of patients. Consequently, the 5 -year survival rate decreases to 5\% (2). Therefore, access to tumor markers of early gastric carcinoma with high sensitivity and specificity is of great importance for the improvement of the diagnostic and survival rates of gastric carcinoma.

MicroRNAs (miRNAs), a type of highly conserved non-protein-coding endogenous small RNAs, bind to the 3'-untranslated region area of the target mRNAs by specific base pairing, which result in the degradation of target mRNAs or inhibition of protein translation. miRNAs participate in posttranscriptional regulation and repress the expression of target genes. miRNAs exhibit tissue specificity and are abnormally expressed in the majority of tumors, including gastric, colorectal and pancreatic carcinoma (3).

miR-155 is a type of miRNA, the expression of which is increased in gastric carcinoma tissues compared with adjacent tissues, and has been associated with lymphatic 
metastasis $(4,5)$. Previous studies investigating the effect of miR-155 on the behavior of tumor cells have focused primarily on proliferation and apoptosis, as opposed to metastasis and invasion of tumor cells. Concurrently, there has been a study suggesting that signal transduction and activators of transcription 3 (STAT3) binds to the promoter of miR-155, and that small hairpin RNA of STAT3 is able to downregulate the expression of miR-155 (6). STAT3, and its phosphorylated form, have been reported to be highly expressed or exhibit increased levels of activity in a number of human malignancies, including gastric carcinoma (7). The expression of phosphorylated (p)-STAT3 has also been closely associated with the metastasis, invasion and prognosis of gastric carcinoma (8-12). It has also been reported that miR-155 is able to regulate the metastasis and invasion of Panc-1 and Capan-2 pancreatic carcinoma cells, and the proliferation and invasion of Hep-2 cells in hepatic carcinoma, through the STAT3 signaling pathway $(13,14)$. It has also been demonstrated that miR-155 may affect the metastasis and invasion of gastric carcinoma cells (15).

Therefore, based on these aforementioned findings, the present study detected the expression of miR-155 in gastric carcinoma cell lines and normal gastric epithelium cell lines using reverse transcription-polymerase chain reaction (RT-PCR), and transfected a miR-155 inhibitor into gastric carcinoma cells to investigate the inhibitory effect of miR-155 on the metastasis as well as invasive ability of gastric carcinoma cells, and to determine whether this effect was mediated through the STAT3 signaling pathway.

\section{Materials and methods}

Cell lines. Human gastric cancer cell lines BGC-823, NCI-N87, SGC-7901, AGS, MKN-45 and immortalized gastric mucosa epithelial cell line GES-1 were purchased from The Cell Bank of Type Culture Collection of Chinese Academy of Sciences (Shanghai, China).

Main reagents and instruments. Anti-rabbit matrix metalloproteinase (MMP) 2, MMP9 monoclonal antibodies were purchased from Epitomics Inc., Abcam (Cambridge, MA, USA). Anti-rabbit STAT3, p-STAT3, vascular endothelial growth factor (VEGF) and suppressor of cytokine signaling 1 (SOCS1) polyclonal antibodies were purchased from Cell Signaling Technology, Inc. (Danvers, MA, USA); MTT was obtained from Gibco; Thermo Fisher Scientific, Inc. (Waltham, MA, USA); fetal bovine serum (FBS) and Dulbecco's modified Eagle's medium (DMEM) culture medium were purchased from Hyclone; GE Healthcare Life Sciences (Logan, UT, USA) and Transwell Chambers from Corning Incorporated (Corning, NY, USA); mini double vertical electrophoresis apparatus, mini transfer electrophoresis apparatus, ChemiDoc $^{\mathrm{TM}}$ XRS Gel Imaging System were purchased from Bio-Rad Laboratories, Inc. (Hercules, CA, USA); and TE2000 fluorescence inverted microscope was obtained from Nikon Corporation (Tokyo, Japan).

$R T-P C R$ validation of miR-155 expression. Total RNA was extracted using the TRIzol ${ }^{\circledR}$ reagent kit (Invitrogen; Thermo Fisher Scientific, Inc.) in the presence of RNAse inhibitory reagents from the cells of BGC-823, NCI-N87, SGC-7901,
AGS, MKN-45 and GES-1. Primer sequences are as follows: miR-155 forward, 5'-GTCGTATCCAGTGCAGGGTCCGAG G-3'; reverse, 5'-TATTCGCACTGGATACGACCCCCTA-3'; GADPH forward, 5'-AGCCACATCGCTCAGACA-3'; reverse, 5'-TGGACTCCACGACGTACT-3'. The RNA was reverse transcribed into cDNA $42^{\circ} \mathrm{C}$ for $10 \mathrm{~min}$ (HiFiScript cDNA, cat.no.CW2569M; Jjiangsu Kangwei Biotech Co.,Ltd.,Jiangsu, China; http://www.cwbiotech.com/article/list/25.jhtml) and PCR amplification was conducted using the One-step RT-PCR kit (UltraSYBR Mixture, cat. no. CW0957M; CWBIO). The primers were added into a $25 \mu \mathrm{l}$ PCR reaction system. The thermocycling conditions were as follows: $94^{\circ} \mathrm{C}$ for $45 \mathrm{sec}$, $59^{\circ} \mathrm{C}$ for $45 \mathrm{sec}$ and $72^{\circ} \mathrm{C}$ for $60 \mathrm{sec}$, for 35 cycles and $72^{\circ} \mathrm{C}$ for $10 \mathrm{~min}$. The relative expression of $\mathrm{miR}-155$ in each group was detected by RT-qPCR and calculated with GAPDH as internal reference using the $2^{-\Delta \Delta \mathrm{Cq}}$ method (16). A total of $\sim 5 \mu$ amplification products were used in the next step, which involved detected of DNA fragments using a $2 \%$ agarose gel. Electrophoresis bands were detected, and the images were captured using an ultraviolet spectrophotometer.

Cell migration assay. Gastric carcinoma AGS and MKN-45 cells $\left(2 \times 10^{5}\right.$ cells) were inoculated in 6-well plates, respectively. When the confluence of the cells reached 50\%, $50 \mathrm{nM}$ miR-155 inhibitor and miR-155 negative control (NC; Shanghai Sangong Pharmaceutical Co., Ltd., Shanghai, China) were transfected into the cells by using Lipofectamine ${ }^{\circledR} 2000$ (Invitrogen; Thermo Fisher Scientific, Inc.). After transfection for $48 \mathrm{~h}$ at $37^{\circ} \mathrm{C}$, the cells were digested and added into the upper Transwell chamber, and the lower chamber continued to be cultured for $24 \mathrm{~h}$ in DMEM medium with 5\% with FBS. Then, the Transwell chamber was removed, washed and fixed with $4 \%$ paraformaldehyde at $4^{\circ} \mathrm{C}$ for $30 \mathrm{~min}$. The cells were stained with $0.1 \%$ crystal violet at room temperature for $5 \mathrm{~min}$, and the number of cells that had passed through the membrane in five fields of view was counted under an inverted optical microscope (x200). The migratory ability of the cells was assessed by calculating the average number of cells per field of view.

Cell invasion assay. The Matrigel gel was evenly spread on the micro-film of the Transwell chamber. The remaining steps were the same as the cell migration assay as mentioned previously. Then, the number of SGC-7901 cells that had passed through the membrane in five fields of view were counted under an inverted optical microscope with a magnification of x200. The invasive ability of the cells was assessed by calculating the average number of cells per field of view.

Western blot analysis. The AGS and MKN-45 cells ( $2 \times 10^{6}$ cells) were inoculated in 6 -well plates at $37^{\circ} \mathrm{C}$ for $2 \mathrm{~h}$. When the confluence of the cells reached 50\%, miR-155 inhibitor and miR-155 NC were transfected into the cells by Lipofectamine 2000. After transfection for $48 \mathrm{~h}$, the cells were scraped and centrifuged with $2,200 \times \mathrm{g}$ for $2 \mathrm{~min}$ at room temperature. Subsequent to the addition of the $200 \mu 1$ radioimmunoprecipitation assay lysate buffer (cat. no. 89900; Thermo Fisher Scientific, Inc.), the cells were vortexed for $30 \mathrm{sec}$. After $40 \mathrm{~min}$, the cells were centrifuged at $4^{\circ} \mathrm{C}$ at $11,180 \mathrm{x} \mathrm{g}$ for $10 \mathrm{~min}$, and then the supernatant was carefully removed to obtain the total protein. The protein concentration was measured using the BCA 
kit (cat. no. CW0014S; CWBIO). The proteins were analyzed using $10 \%$ SDS-PAGE, and then transferred to a polyvinylidene fluoride membrane. Following blocking for $2 \mathrm{~h}$ at $37^{\circ} \mathrm{C}$ with $5 \%$ skimmed milk powder, the membrane was immersed and incubated in primary antibody (Stat3 rabbit mAb; cat. no. 12640; dilution, 1:1,000; Cell Signaling Technology, Inc.) solution overnight at $4^{\circ} \mathrm{C}$ and washed by Tris Buffered Saline Tween three times. Following rinsing, the membrane was immersed and incubated in the secondary antibody solution (goat anti-rat IgG; cat. no. ZB-2305; dilution, 1:2,000; OriGene Technologies, Inc., Rockville, MD, USA) at room temperature for $1-2 \mathrm{~h}$. The membrane was removed and washed by Tris Buffered Saline Tween for 4 times, and then the ECL solution (cat. no. RJ239678; Thermo Fisher Scientific, Inc.) was added. Subsequently, the membrane was exposed in the gel imaging system (ChemiDoc XRS+; Bio-Rad Laboratories, Inc.). The gray value of each antibody band was detected with Quantity One software version 4.62 (Bio-Rad Laboratories, Inc., Hercules, CA, USA).

Statistical analysis. Mean and standard deviation (SD) values were used to summarize continuous variables. Independent $\mathrm{t}$-tests were used to determine the differences between groups. $\mathrm{P}<0.05$ was considered to indicate a statistically significant difference. All analyses were performed using SPSS software, version 17.0 (SPSS, Inc., Chicago, IL, USA).

\section{Results}

Expression of miR-155 in gastric carcinoma cells. The expression levels (mean $\pm \mathrm{SD}$ ) of miR-155 in BGC-823, NCI-N87, SGC-7901, AGS and MKN-45 cells were $0.22 \pm 0.03$, $0.36 \pm 0.03,0.43 \pm 0.02,0.86 \pm 0.05$ and $0.94 \pm 0.04$, respectively, which were significantly increased compared with the GES-1 cell line (0.13 \pm 0.02 ; all $\mathrm{P}<0.05$; data not shown), as confirmed by RT-PCR. AGS and MKN-45 were selected for subsequent experiments due to the high expression levels of miR-155.

Effect of miR-155 on the migratory ability of gastric carcinoma cells. The effect of miR-155 on the migration of gastric carcinoma cells is presented in Fig. 1. The cell counts (mean \pm SD) of the AGS cell line were $98.99 \pm 9.13$ in the miR-155 NC group and 45.32 \pm 4.32 in the miR-155 inhibitor group ( $\mathrm{P}<0.01$; Fig. $1 \mathrm{~A}$ and $\mathrm{B})$; For the MKN-45 cell line, the counts were $129.99 \pm 10.12$ and $50.36 \pm 5.2$ in the miR-155 NC and miR-155 inhibitor groups, respectively ( $\mathrm{P}<0.01$; Fig. 1C-E).

Effect of miR-155 on the invasive ability of gastric carcinoma cells. The effect of miR-155 on the invasion of gastric carcinoma cells is indicated in Fig. 2. The cell counts of the AGS cell line were $70.25 \pm 7.94$ in the miR-155 $\mathrm{NC}$ group and $40.68 \pm 4.73$ in the miR-155 inhibitor group $(\mathrm{P}<0.05$; Fig. $2 \mathrm{~A}$ and $\mathrm{B})$; For the MKN-45 cell line, the counts were $84.63 \pm 8.12$ and $40.35 \pm 4.29$ in the miR-155 NC and miR-155 inhibitor groups, respectively $(\mathrm{P}<0.05$; Fig. 2C-E).

Effect of miR-155 on the level of phosphorylated (p-)STAT3. As observed in Fig. 3, transfection of the miR-155 inhibitor was able to significantly decrease the level of p-STAT3 in AGS (Fig. 3A) and MKN-45 cells (Fig. 3B) compared with the cells transfected with miR-155 NC (both $\mathrm{P}<0.05)$.
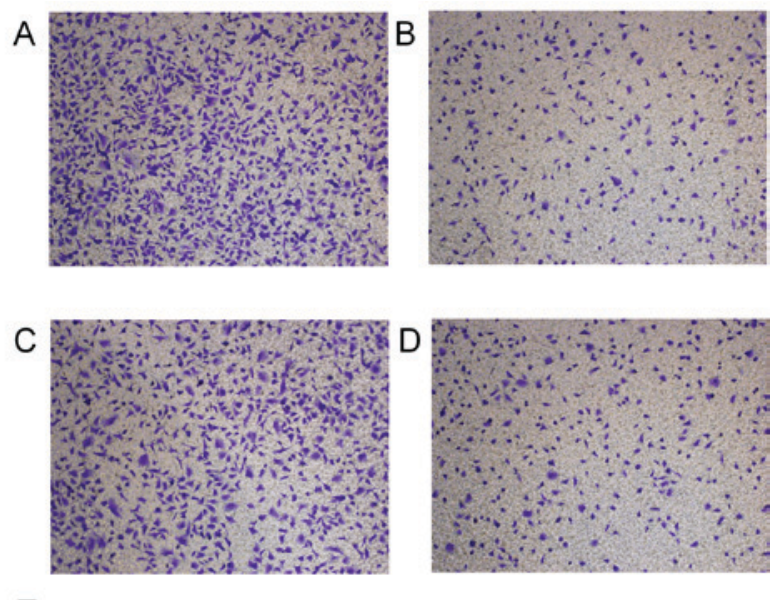

E

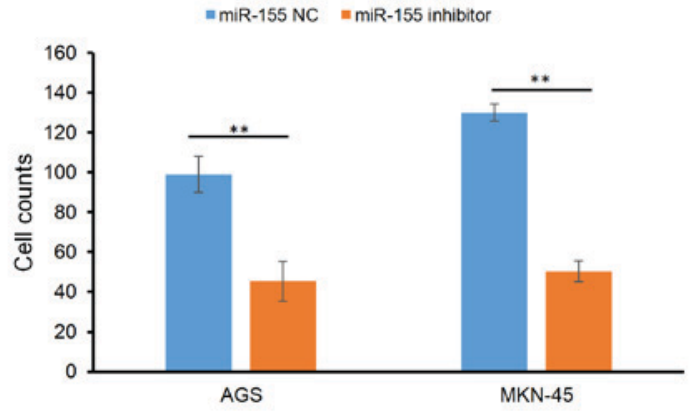

Figure 1. Effect of miR-155 on the migratory ability of gastric carcinoma cells. Effect of (A) miR-155 NC and (B) miR-155 inhibitor on AGS cells. Effect of (C) miR-155 and (D) miR-155 inhibitor on MKN-45 cells. (E) Cell counts in the two groups. ${ }^{* *} \mathrm{P}<0.01$. NC, negative control; miR, miRNA. Magnification, $\mathrm{x} 200$.
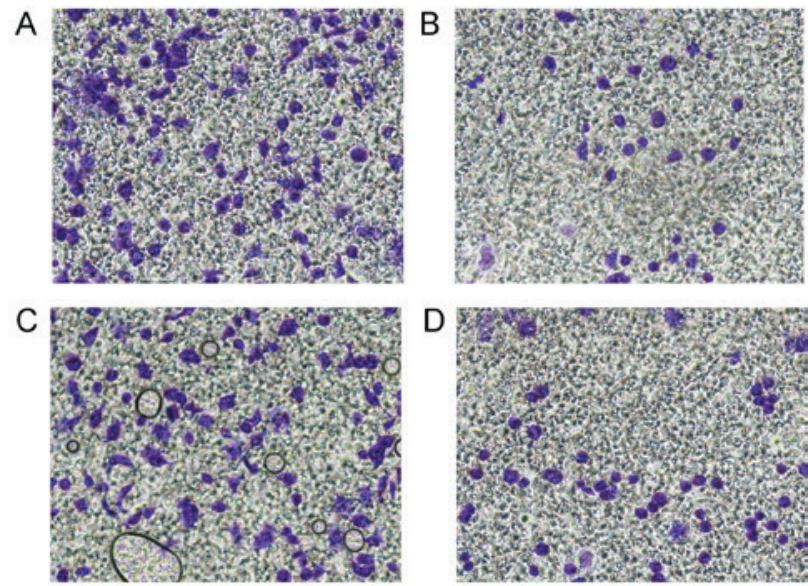

$\mathrm{E}$

$=$ miR-155 NC $=$ miR-155 inhibitor

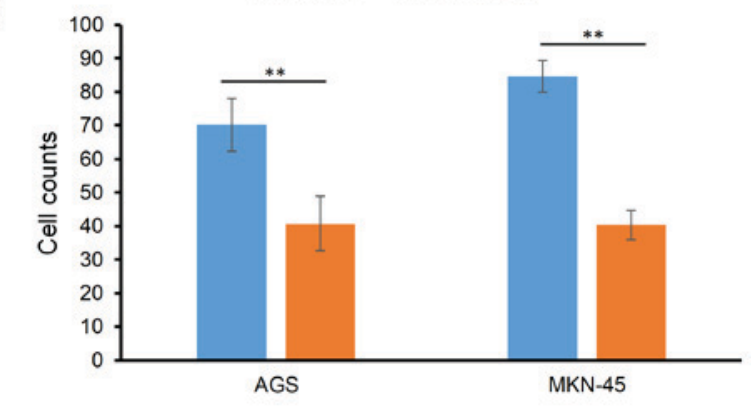

Figure 2. Effect of miR-155 on the invasive ability of gastric carcinoma cells. Effect of (A) miR-155 NC and (B) miR-155 inhibitor on AGS cells. Effect of (C) miR-155 and (D) miR-155 inhibitor on MKN-45 cells. (E) Cell counts in the two groups. ${ }^{* *} \mathrm{P}<0.01$. NC, negative control; miR, miRNA. Magnification, $\mathrm{x} 200$. 
A

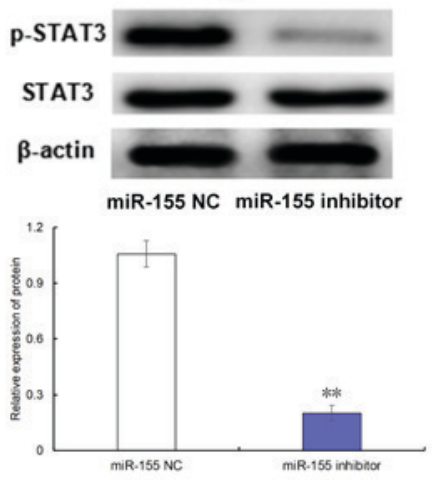

B

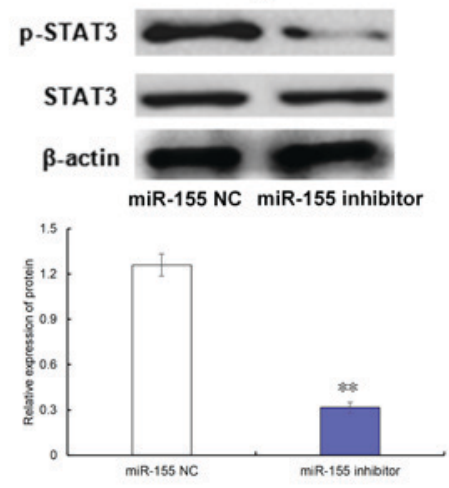

Figure 3. Effect of miR-155 on the level of p-STAT3 in gastric carcinoma cells. (A) AGS cells; (B) MKN-45 cells. ** P<0.01. miR, miRNA; NC, negative control; p-, phosphorylated; STAT3, signal transducer and activator of transcription 3.
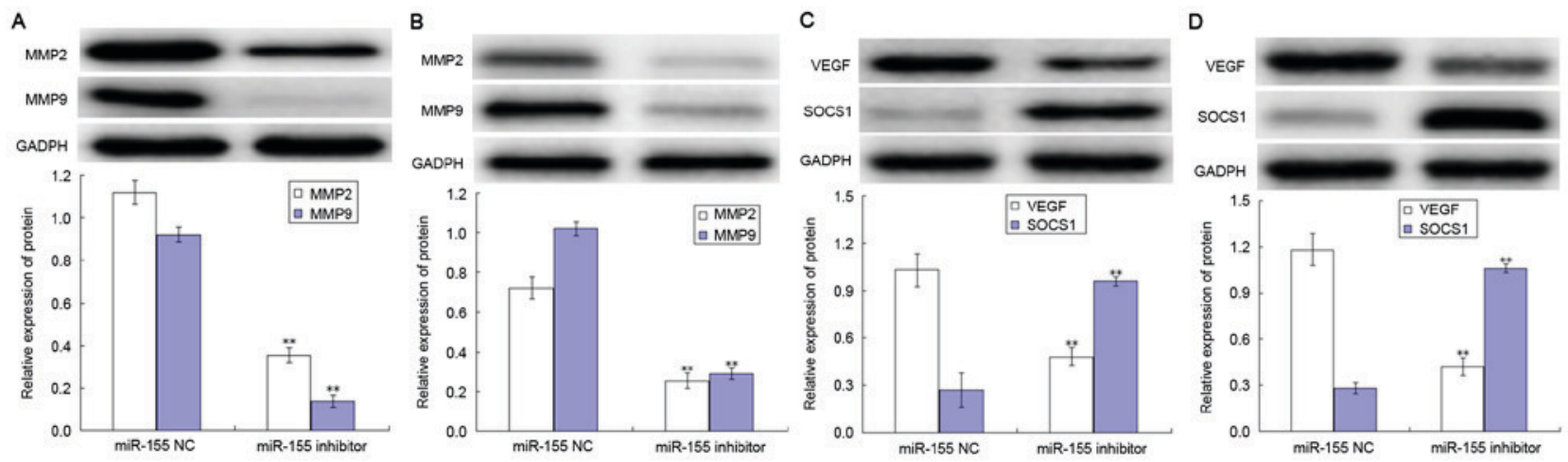

Figure 4. Effect of miR-155 on the expression levels of MMPs, VEGF and SOCS1 in gastric carcinoma cells. The levels of MMP-2 and MMP-9 expression in (A) AGS cells and (B) MKN-45 cells. The levels of VEGF and SOCS1 expression in (C) AGS cells and (D) MKN-45 cells. miR, miRNA; MMP, matrix metallopeptidase; VEGF, vascular endothelial growth factor; SOCS1, suppressor of cytokine signaling $1 .{ }^{* *} \mathrm{P}<0.01$.

Effect of miR-155 on the expression levels of MMPs, VEGF and SOCS1. The levels of MMP-2, MMP-9, VEGF and SOCS1 expression in AGS and MKN-45 cells are presented in Fig. 4. The expression levels of MMP2 and MMP9 were decreased following transfection with miR-155 in the AGS and MKN-45 cell lines, compared with respective negative control group (both $\mathrm{P}<0.05$; Fig. $4 \mathrm{~A}$ and $\mathrm{B}$ ). Notably, transfection with the miR-155 inhibitor was able to decrease the level of VEGF expression in AGS and MKN-45 cells, whilst increasing the level of SOCS1 expression compared with negative control group (all $\mathrm{P}<0.05$; Fig. 4C and D).

\section{Discussion}

The abnormal expression of miRNA is closely associated with various types of human tumors (2). miRNA is a key factor which affects the formation and development of tumors. miRNA is a type of multifunctioning RNA molecule, located in the non-coding region of chromosome q21 (17). miRNAs participate in a number of biological processes, including hematopoiesis, inflammation and regulation of immune responses $(18,19)$. Previous studies had hypothesized that miR-155 exhibited a carcinogenic effect, and high expression of miR-155 has been reported in breast, hepatic, pancreatic and colorectal carcinoma (3). Liu et al (5) observed that the expression of miR-155 was increased in gastric carcinoma tissues compared with corresponding non-tumor normal tissues using RT-PCR analysis. Song et al (4) additionally verified that the expression of miR-155 was increased in cases of gastric carcinoma with lymphatic metastasis, and the expression level of miR-155 was independent of the gender, age, tumor size, level of invasion, tumor node metastasis (TNM) stage and vascular invasion, but miR-155 expression was associated with lymphatic metastasis. Therefore, they concluded that miR-155 is closely associated with the formation and development of gastric carcinoma (4). Based on the aforementioned findings, the present study focused on the expression of miR-155 in 6 gastric carcinoma (BGC-823, NCI-N87, SGC-7901, AGS and MKN-45) cell lines and the normal GES-1 cell line. The results indicated that miR-155 expression was the highest in MKN-45 cells, which was in accordance with the results of Liu et al (5) and Song et al (4). The unfavorable prognosis and the low five-year survival rate are primarily based on the invasion and metastasis rates of the carcinoma cells. Therefore, the present study also investigated the effect of miR-155 on the invasive and metastatic ability of gastric carcinoma cells.

The active form of STAT3 binds to the gene promoter of miR-155 in chronic lymphocytic leukemia (6). It was reported that the STAT3 small hairpin RNA may decrease the expression of miR-155 (6). Huang et al (14) suggested that miR-155 regulated the migration and invasion of pancreatic carcinoma Panc-1 and Capan-2 cells via the STAT3 signaling pathway. 
Zhao et al (13) demonstrated that miR-155 promoted the proliferation and invasion of hepatic carcinoma Hep-2 cells through increasing the activation of the STAT3 signaling pathway. Therefore, the present study hypothesized that miR-155 may affect the migratory and invasive abilities of gastric carcinoma via the STAT3 signaling pathway. Located on chromosome 12, STAT3 is one of the members of the STAT family. STAT3 is activated by phosphorylation of a tyrosine residue, which is induced by the binding of cytokines or growth factors or activation of oncogenes (20). STAT3 binds with the tyrosine residue of p-STAT3 and forms a dimer through the Src homolog 2 domain. Subsequently, the dimer is translocated into the nucleus to bind to the promoter region of the target genes and regulates the transcription of these genes. Consequently, proliferation is promoted and apoptosis is blocked. Other effects include the induction of immune evasion, promotion of angiogenesis and induction of invasion and metastasis of tumor cells. STAT3 is involved in the initiation and development of tumors (9). p-STAT3 is an independent prognostic factor of gastrointestinal tumors, the expression of which is high in tumor cells, and is closely associated with low overall survival and disease-free survival rates $(10,12)$. The expression of p-STAT3 in gastric carcinoma tissues is significantly increased compared with adjacent tissues, and is associated with lymphatic metastasis (8). STAT3 expression increases in severe atypical hyperplasia tissues, gastric carcinoma tissues and lymph metastasis (21). This finding suggests that there is a positive correlation between STAT3 and histodifferentiation and lymphatic metastasis.

A meta-analysis which included 5,757 patients with gastric cancer indicated that the 5-year survival rate of patients with high expression levels of STAT3 and MMP-9 was decreased, compared with the low expression levels of STAT3 and MMP-9 and was associated with lymphatic metastasis, distant metastasis, differentiation, tumor size and high TNM stage, suggesting that the expression level of p-STAT3 is closely associated with the formation and development of gastric carcinoma, and is positively correlated with lymphatic metastasis (11). The hypothesis is that the decreasing the level of p-STAT3 may inhibit the metastasis and invasion of gastric carcinoma cells. The results of the present study indicated that decreasing the expression of miR-155 may decrease the level of p-STAT3, and consequently decreases the metastatic and invasive abilities of gastric carcinoma AGS and MKN-45 cells. Therefore, miR-155 affects the metastatic and invasive abilities of gastric carcinoma cells via the STAT3 signaling pathway.

The STAT3 signaling pathway is regulated by negative feedback by SOCS (22). SOCS1 binds to Janus kinase and then inhibits its activity, which results in the decrease of STAT3 activity or the level of p-STAT3. Souma et al (23) demonstrated that adenovirus-expressing SOCS1 may decrease the level of p-STAT3 in gastric carcinoma NUGC-3 and AGS cell lines and inhibit the proliferation and metastasis of carcinoma cells. miR-155 may promote the proliferation and invasion of Hep-2 hepatic carcinoma cells by increasing the expression of STAT3 and decreasing the expression of SOCS1 (13). The result of the present study indicated that decreasing the expression of miR-155 in gastric carcinoma cell lines may significantly increase the expression of SOCS1, suggesting that miR-155 inhibition weakens the invasive and metastatic abilities of AGS and MKN-45 cells by increasing the expression of SOCS1 and decreasing the level of p-STAT3.

STAT3 promotes the metastasis, angiogenesis and invasion of tumors by increasing the expression of B-cell lymphoma 2-like protein 1, myeloid cell leukemia 1, survivin, cyclinD1, VEGF and MMP-2 (24-27). Niu et al (25) and Wei et al (24) revealed the presence of STAT3 binding sites on the VEGF promoter, and that a mutation in that site resulted in a loss of activity of the VEGF promoter, which is mediated by STAT3. This finding suggested that VEGF was a downstream target gene of STAT3.

The formation and development of tumor depends on the nutrient supply from angiogenesis (28). VEGF serves a pivotal role in that process, and also mediates the invasion and metastasis of tumor cells. The expression of STAT3, p-STAT3 and VEGF-D in gastric carcinoma tissues was increased compared with adjacent tissues and GES-1 (29). The downregulated expression of STAT3 may decrease the expression of VEGF-D and thereby inhibit lymphatic metastasis. Xie et al (27) reported the presence of STAT3 binding sites in the MMP2 promoter. It was demonstrated that STAT3 was able to increase the expression of MMP2, to promote the invasion and metastasis of melanoma cells in nude mice (30).

MMPs are the most important proteinase in this process, as they are the key enzymes involved in the invasion and metastasis of tumor cells (31). MMP-2 is able to digest the collagen IV component of gelatin in extracellular matrix to assist tumor cells to invade through the damaged basement membrane (32). MMP-2 is also able to induce capillary hyperplasia, which is characteristic of tumor cell invasion and metastasis. MMP-9 is a type of proteolytic enzyme secreted by a various types of cells, and it has one of the highest molecular weight among all members of the MMP family (31). MMP-9 digests the extracellular matrix and basement membrane, which consequently increases the motility ability of cells and promotes the spread and metastasis of tumor cells (31). There is a positive association between the expression of p-STAT3 in SNU-638 and MKN1 cells, and MMP9, suggesting that decreasing the level of phosphorylated STAT3 may decrease the expression of VEGF, MMP2 and MMP9, thereby inhibiting the invasion and metastasis of gastric carcinoma cells (33). The results of the present study indicate that the downregulation of miR-155 expression in gastric carcinoma cell lines was able to significantly decrease the expression of VEGF, MMP2 and MMP9, thereby inhibiting the invasion and metastasis of gastric carcinoma cells.

In conclusion, miR-155 is highly expressed in gastric carcinoma cell lines. The downregulation of miR-155 expression may significantly decrease the level of p-STAT3 and the expression of VEGF, MMP2 and MMP9, as well as increasing the expression of SOCS1.

\section{Acknowledgements}

Not applicable.

\section{Funding}

No funding was received. 


\section{Availability of data and materials}

The datasets used and/or analyzed during the current study are available from the corresponding author on reasonable request.

\section{Ethics approval and consent to participate}

Not applicable.

\section{Authors' contributions}

ZMS conceived and designed the experiments. Data collection and experiments were performed by HW, YL and QN. HW and YL analyzed the data and all authors contributed to the writing of the manuscript.

\section{Consent for publication}

Not applicable.

\section{Competing interests}

The authors declare that they have no competing interests.

\section{References}

1. Xia Y, Zhang M, Zhang X and Liu X: A systematic review and meta-analysis of runt-related transcription factor 3 gene promoter hypermethylation and risk of gastric cancer. J Cancer Res Ther 10(Suppl): S310-S313, 2014.

2. Jiang C, Chen X, Alattar M, Wei J and Liu H: MicroRNAs in tumorigenesis, metastasis, diagnosis and prognosis of gastric cancer. Cancer Gene Ther 22: 291-301, 2015.

3. Wu LT, Cui L, Wang YL and Huang LM: Research progress on miR-155, EMT and tumour invasion/metastasis. Biotechnol Bull 30: 55-59, 2014.

4. Song J, Wang H, Fu HX, Meng S, Xu YX and Xu W: MiR-155 expression in gastric cancer tissues and its clinical significance. Chin J Gen Surg 21: 1236-1239, 2012 (In Chinese).

5. Liu L, Chen Q, Lai R, Wu X, Wu X, Liu F, Xu G and Ji Y: Elevated expression of mature miR-21 and miR-155 in cancerous gastric tissues from Chinese patients with gastric cancer. J Biomed Res 24: 187-197, 2010

6. Li P, Grgurevic S, Liu Z, Harris D, Rozovski U, Calin GA Keating MJ and Estrov Z: Signal transducer and activator of transcription-3 induces microRNA-155 expression in chronic lymphocytic leukemia. PLoS One 8: e64678, 2013.

7. Ji K, Zhang L, Zhang M, Chu Q, Li X and Wang W: Prognostic value and clinicopathological significance of p-stat3 among gastric carcinoma patients: A systematic review and meta-analysis. Medicine (Baltimore) 95: e2641, 2016.

8. Zhang XM, Zhou C, Gu H, Yan L and Zhang GY: Correlation of RKIP, STAT3 and cyclin D1 expression in pathogenesis of gastric cancer. Int J Clin Exp Pathol 7: 5902-5908, 2014.

9. Li MX, Bi XY, Huang Z, Zhao JJ, Han Y, Li ZY, Zhang YF, Li Y, Chen X, Hu XH, et al: Prognostic role of phospho-STAT3 in patients with cancers of the digestive system: A systematic review and meta-analysis. PLoS One 10: e0127356, 2015.

10. Inokuchi M, Murayama T, Hayashi M, Takagi Y, Kato K, Enjoji M, Kojima K, Kumagai J and Sugihara K: Prognostic value of co-expression of STAT3, mTOR and EGFR in gastric cancer. Exp Ther Med 2: 251-256, 2011.

11. Chen J, Liu X, Jiao H, Peng L, Huo Z, Yang W, Shen Q, Li T and Liu Q: Prognostic and clinical significance of STAT3 and MMP9 in patients with gastric cancer: A meta-analysis of a Chinese cohort. Int J Clin Exp Med 8: 546-557, 2015.

12. Liu Y, Deng J, Luo X, Pan Y, Zhang L, Zhang R and Liang $\mathrm{H}$ Overexpression of SMYD3 was associated with increased STAT3 activation in gastric cancer. Med Oncol 32: 404, 2015.
13. Zhao XD, Zhang W, Liang HJ and Ji WY: Overexpression of miR-155 promotes proliferation and invasion of human laryngeal squamous cell carcinoma via targeting SOCS1 and STAT3. PLoS One 8: e56395, 2013.

14. Huang C, Li H, Wu W, Jiang T and Qiu Z: Regulation of miR-155 affects pancreatic cancer cell invasiveness and migration by modulating the STAT3 signaling pathway through SOCS1. Oncol Rep 30: 1223-1230, 2013.

15. Wan J, Xia L, Xu W and Lu N: Expression and function of miR-155 in diseases of the gastrointestinal tract. Int J Mol Sci 17: E709, 2016.

16. Livak KJ and Schmittgen TD: Analysis of relative gene expression data using real-time quantitative PCR and the 2(-Delta Delta C(T)) method. Methods 25: 402-408, 2001.

17. Ambros V: The functions of animal microRNAs. Nature 431: 350-355, 2004

18. Seddiki N, Brezar V, Ruffin N, Lévy Y and Swaminathan S: Role of miR-155 in the regulation of lymphocyte immune function and disease. Immunology 142: 32-38, 2014.

19. Jurkovicova D, Magyerkova M, Kulcsar L, Krivjanska M, Krivjansky V, Gibadulinova A, Oveckova I and Chovanec M: miR-155 as a diagnostic and prognostic marker in hematological and solid malignancies. Neoplasma 61: 241-251, 2014.

20. Buettner R, Mora LB and Jove R: Activated STAT signaling in human tumors provides novel molecular targets for therapeutic intervention. Clin Cancer Res 8: 945-954, 2002.

21. Zhang L, Li J, Wang Q, Meng G, Lv X, Zhou H, Li W and Zhang J: The relationship between microRNAs and the STAT3-related signaling pathway in cancer. Tumour Biol 39: 1010428317719869, 2017.

22. Alexander WS, Starr R, Metcalf D, Nicholson SE, Farley A, Elefanty AG, Brysha M, Kile BT, Richardson R, Baca M, et al: Suppressors of cytokine signaling (SOCS): Negative regulators of signal transduction. J Leukoc Biol 66: 588-592, 1999.

23. Souma Y, Nishida T, Serada S, Iwahori K, Takahashi T, Fujimoto M, Ripley B, Nakajima K, Miyazaki Y, Mori M, et al: Antiproliferative effect of SOCS-1 through the suppression of STAT3 and p38 MAPK activation in gastric cancer cells. Int J Cancer 131: 1287-1296, 2012.

24. Wei D, Le X, Zheng L, Wang L, Frey JA, Gao AC, Peng Z, Huang S, Xiong HQ, Abbruzzese JL and Xie K: Stat3 activation regulates the expression of vascular endothelial growth factor and human pancreatic cancer angiogenesis and metastasis. Oncogene 22: 319-329, 2003

25. Niu G, Wright KL, Huang M, Song L, Haura E, Turkson J, Zhang S, Wang T, Sinibaldi D, Coppola D, et al: Constitutive Stat3 activity up-regulates VEGF expression and tumor angiogenesis. Oncogene 21: 2000-2008, 2002.

26. Li S, Priceman SJ, Xin H, Zhang W, Deng J, Liu Y, Huang J, Zhu W, Chen M, Hu W, et al: Icaritin inhibits JAK/STAT3 signaling and growth of renal cell carcinoma. PLoS One 8: e81657, 2013

27. Xie TX, Huang FJ, Aldape KD, Kang SH, Liu M, Gershenwald JE, Xie K, Sawaya R and Huang S: Activation of stat 3 in human melanoma promotes brain metastasis. Cancer Res 66: 3188-3196, 2006.

28. GuptaMK andQinRY:Mechanism and its regulation of tumor-induced angiogenesis. World J Gastroenterol 9: 1144-1155, 2003.

29. Deng J, Cui J, Jiang N, Zhang R, Zhang L, Hao X and Liang H: STAT3 regulation the expression of VEGF-D in HGC-27 gastric cancer cell. Am J Transl Res 6: 756-767, 2014.

30. Fofaria NM, Srivastava SK: Critical role of STAT3 in melanoma metastasis through anoikis resistance. Oncotarge 5: 7051-7064, 2014.

31. Deryugina EI and Quigley JP: Tumor angiogenesis: MMP-mediated induction of intravasation- and metastasis-sustaining neovasculature. Matrix Biol 44-46: 94-112, 2015.

32. Mook OR, Frederiks WM and Van Noorden CJ: The role of gelatinases in colorectal cancer progression and metastasis. Biochim Biophys Acta 1705: 69-89, 2004.

33. Yoon J, Cho SJ, Ko YS, Park J, Shin DH, Hwang IC, Han SY, Nam SY, Kim MA, Chang MS, et al: A synergistic interaction between transcription factors nuclear factor- $\mathrm{\kappa B}$ and signal transducers and activators of transcription 3 promotes gastric cancer cell migration and invasion. BMC Gastroenterol 13: 29, 2013.

This work is licensed under a Creative Commons Attribution-NonCommercial-NoDerivatives 4.0 International (CC BY-NC-ND 4.0) License. 